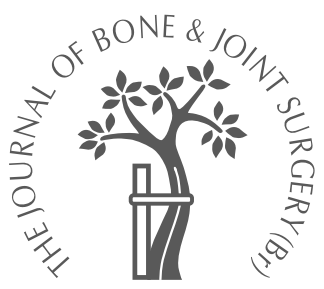

S. E. Farmer,

P. J. Woollam,

J. H. Patrick,

A. P. Roberts,

W. Bromwich

From The Robert

Jones and Agnes

Hunt Orthopaedic

Hospital, Oswestry,

England

\title{
- ANNOTATION
}

\section{Dynamic orthoses in the management of joint contracture}

Joint contractures may occur following treatment in an intensive-care unit ${ }^{1}$ after operations on the leg such as a knee replacement, ${ }^{2-4}$ after bed-care in the elderly ${ }^{5}$ or secondary to neurological, ${ }^{6-8}$ neuromuscular ${ }^{9}$ and arthritic conditions. ${ }^{10}$ Clinical management is aimed at preventing contractures or limiting their progress. A number of methods such as passive stretching, splinting, the application of serial plasters, injection of botulinum toxin, electrical stimulation and surgery have been used to manage contractures. They tend to recur in neurological conditions after the application of serial plasters, injections of botulinum toxin or tenotomies. ${ }^{11}$ This may be due to continuation of the central underlying cause. Distinction must be made between contractures resulting from gravitational and postural causes and those arising from disease processes. Either can produce impairment, which may interfere with effective treatment.

During healing after injury, scar tissue contracts and this may produce deformity. ${ }^{12}$ In the case of neuromuscular disease, the view that it is only muscular imbalance or spasticity at a joint which causes contracture has been modified since changes in the soft tissues have now been recognised. ${ }^{13}$

Rehabilitation both within hospital and in the community can be inhibited by the presence of contractures. There are few studies on the incidence of contractures. ${ }^{1,3,5,6}$ Treatment or prophylaxis is the more usual focus of clinical examination ${ }^{9,10,12,14,15}$ because of the expense to patients and the health service due to the delays in rehabilitation. The Orthotic Research and Locomotor Assessment Unit (ORLAU) at the Robert Jones and Agnes Hunt Orthopaedic Hospital has introduced and patented ${ }^{16}$ an orthotic treatment system ${ }^{17,18}$ and while this was under development, other similar orthoses became available.

In this review we discuss the merits of these corrective dynamic orthoses in the treatment of joint contracture of whatever cause.

\section{Pathophysiological considerations of contracture}

Contractures may develop as a result of muscle spasm limiting the position of the joint or by immobilisation of the joint in an inappropriate position. After trauma involving a joint, stiffness or limitation of movement may occur. ${ }^{4}$ The varied aetiologies appear to cause similar pathophysiological changes with inter-relationships between immobilisation, muscle weakness and spasticity. ${ }^{11}$ Contractures can be prevented or reduced by stretching, which has been shown to maintain or increase the numbers of muscle sarcomeres in series, ${ }^{19}$ increase tendon length ${ }^{20}$ and maintain the elasticity of the connective tissue. ${ }^{21}$ The stretching effect on the anatomical structures at the joint is obvious, but the connective tissue enclosing the muscle cell or in the perimysium also alters. ${ }^{22}$ It has also been recognised that there is an excessive amount of fibrous tissue present in spastic muscle in cerebral palsy. ${ }^{23}$ Alter $^{24}$ observed that when connective tissue is held under tension at a constant length it gradually relaxes, resulting in loss of tension. Thus, any technique such as static splinting which holds the joint in a fixed position will lose its stretching effect after a short period. If connective tissue is held under constant tension it undergoes creep and lengthens. These effects are used by dynamic orthoses to stimulate continuous lengthening.

\section{Orthotic treatment of contracture}

Static or fixed-position orthoses. Traditionally, contractures have been 'prevented' by using splints which hold the joint at the limit of its range of movement. Flowers and LaStayo ${ }^{25}$ have shown that total end-of-range time is directly related to the increase in range of movement for patients with post-traumatic contractures of finger joints.

McClure, Blackburn and Dusold ${ }^{26}$ described the use of splints in the treatment of joint stiffness and discussed the frequency, duration and intensity of treatment. Soft night 


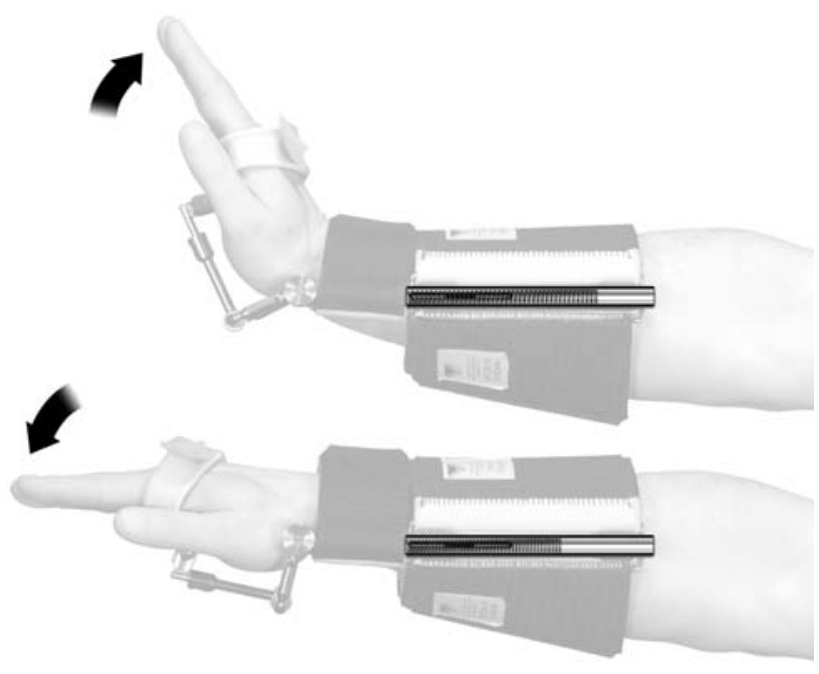

Fig. 1

Diagram of the Dynasplint which uses conventional coil springs.

splinting was used by Anderson et $\mathrm{al}^{27}$ to reduce severe flexion contractures of the knee in children with spastic quadriplegia. Passive stretching and night splinting were shown by Scott et al ${ }^{28}$ to delay the development of contractures in the early stages of Duchenne muscular dystrophy. McDonald ${ }^{9}$ agreed that splinting is an important means of delaying contractures in these patients.

Bonutti et $\mathrm{al}^{29}$ treated post-traumatic contractures of the elbow using an orthosis which allowed an incremental displacement. Gelinas et $\mathrm{al}^{30}$ used a turnbuckle splint and others have employed an adjustable ankle-foot orthosis to stretch equinus contractures in patients after traumatic cerebral injury or a stroke. ${ }^{31}$

Dynamic orthoses. The 'Dynasplint' (Dynasplint Systems Inc, Severna Park, Maryland) (Fig. 1), which uses a spring to generate a turning moment at the joint, has been developed and used in the treatment of contractures of the upper and lower limb. Hepburn ${ }^{32}$ reported measured improvement in contractures in 13 patients in whom a splint was used for eight to 12 hours per day. Steffen and Mollinger ${ }^{33}$ used corrective splints for three hours on five days per week for a period of five months, but found no demonstrable benefit from this regime.

Contractures in arthrogryposis have been managed by using a dynamic splinting system which incorporated a gas spring, as used to power a car tailgate. ${ }^{18}$ A similar type of custom-made orthosis, the contracture correction device (CCD) (see Fig. 2), has been used to provide a continuous stretch. ${ }^{34-36}$ Early experience in the treatment of children with contractures due to cerebral palsy indicated that some correction was achieved by using the orthosis for only one hour per day over a period of three months. ${ }^{16,37}$ The Ultraflex system (Ultraflex Systems Inc, Dowington, Pennsyl-

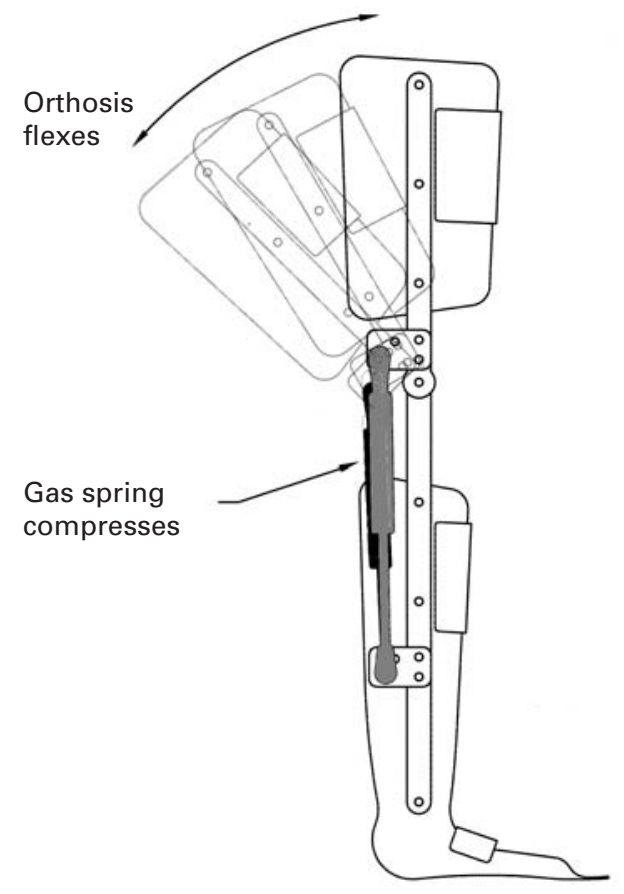

Fig. 2

Diagram of the gas-spring ORLAU CCD.

vania) has been used in a patient with a spinal cord injury at C5/6. ${ }^{38,39}$ Nuismer, Ekes and Holm ${ }^{40}$ treated 18 contractures (two wrists, 12 elbows and four knees) by stretching orthoses (9 Dynasplint, 8 Ultraflex and 1 turnbuckle) for a mean of 6.47 hours per day (1 to 12 ). Only two patients showed no improvement, with the remainder making gains of between $6^{\circ}$ and $66^{\circ}$ in range of movement after three months. Our experience of similar splinting techniques for one hour per day suggests that such treatment can be used for any type of contracture.

Types of orthotic spring hinge. There are three main types of spring used to provide the force in stretching orthoses.

Coil spring (Fig. 1). Conventional metal coil springs produce a linear force which is proportional to the change in length of the spring, although the force increases at a much higher rate than with gas springs. The Dynasplint uses this type of spring.

Gas spring (Fig. 2). The linear force produced by a gas spring depends on the gas pressure and usually rises by $30 \%$ at full compression. This type of spring is used in the ORLAU device.

Clockwork (flat) spring (Fig. 3). The turning moment, or torque, produced by the clockwork spring is almost constant throughout the functional range. Commercially, Ultraflex systems ${ }^{39}$ and EMPI stock orthoses (EMPI, St. Paul, Minnesota $)^{41}$ use this method.

When these springs are incorporated into an orthosis the torque produced varies with the angle of the joint. The centre of the clockwork spring can be located over the centre of 


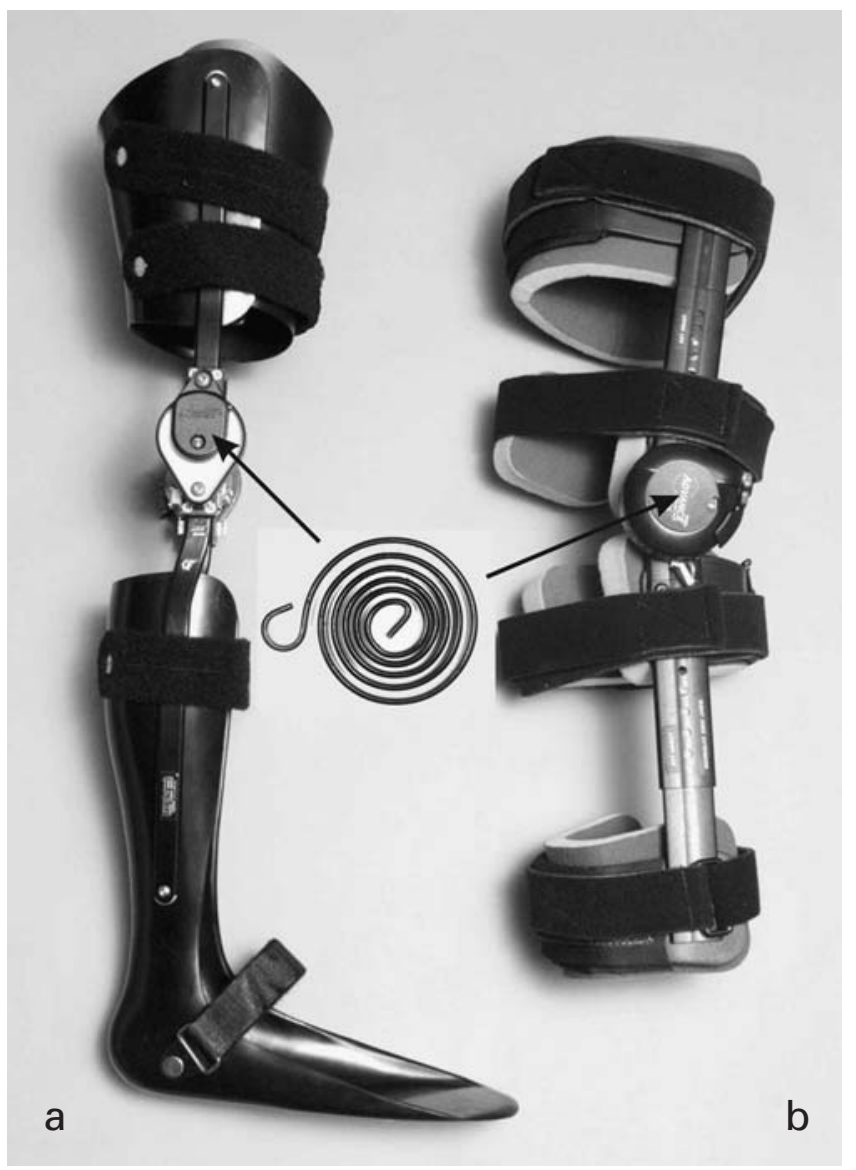

Fig. 3

Diagram of a) the Ultraflex and b) the EMPI system which use clock springs.

rotation of the joint so that the torque produced is directly related to the strength of the spring and the angle of the joint. Spiral springs and gas springs are attached to either side of the orthotic joint. Thus the torque relates not only to the characteristics of the spring but also to its varying distance from the centre of the joint and hence its moment arm.

Torque adjustment provided by the splint. The torque generated by the ORLAU CCD (Fig. 2) depends on the position of the gas springs, which can be fitted on either or both the lateral and medial aspects of the knee with a choice of three positions on each side. These deliver 4,5 or $6 \mathrm{Nm}$ of torque at full extension so that by using one or two springs, values of between 4 and $12 \mathrm{Nm}$ can be selected. The assembly requires engineering tools which are easily available to change the position of the spring, and this discourages adjustment by the user.

The Dynasplint (Fig. 1) and Ultraflex (Fig. 3a) orthoses include a simple tool with every device sold, and the EMPI (Fig. 3b) brace incorporates a handle which is turned to provide adjustment and which folds away when not in use. Therapists can easily make adjustments and may choose to instruct the user in adjusting the torque to ease application or to increase the stretch when this can be tolerated. The Ultraflex system offers a choice of spring units designed specifically for paediatric use and also a range of adult joints with low, medium and high ranges of spring strength. In each case, a scale from 0 to 7 (Ultraflex) or 0 to 10 (Dynasplint and EMPI) indicates the level of adjustment which is selected. The Ultraflex system provides graphs in a manual for clinicians which relate the points on the scale to a torque measured in conventional units, e.g. Newton metres $(\mathrm{Nm})$ and inch pounds (in.lb).

Joints treated. The Ultraflex system also offers a reversible unit which can be used to give assistance in both flexion and extension. Most of the other systems are intended to assist extension only. It also includes the widest range of components with joints suitable for use with the knee, the ankle and a variety of upper-limb orthoses. Dynasplint orthoses are available for the knee, elbow and wrist.

Clinical factors. Spring mechanisms offer the advantage of an immediate dynamic response to physiological activity by applying a measurable and clinically controlled level of torque. Their tension can be set so that the user can overcome the stretching effect. If muscle spasm occurs the spring will give way but restore the limb to the stretched position once the spasm has passed.

Interface design. The force generated by these springs is transmitted to the limb by the orthosis. A large area of interface between the surface of the limb and the orthosis reduces the pressure on the skin and the risk of consequent tissue damage. This area of contact should extend as far distally as possible from the centre of rotation of the joint to be stretched, thereby taking advantage of the maximum lever arm. The interface can be of leather, fabric, neoprene or polypropylene. The orthotic structure is completed with metal side members.

Custom-made or stock. In choosing between custom-made and stock devices, the immediacy of the benefit from the provision of a stock is weighed against the intimate fit and intrasegmental alignment of the custom-made device. For instance, it is important when stretching triceps surae to maintain correct calcaneal alignment which is best controlled by an orthosis made from a cast.

Ease of application. An important factor for many patients is the ease of use of the orthosis. This is enhanced if there is a simple method of locking in mid-range to facilitate correct alignment between the centres of the orthosis and the joint during application and removal. The EMPI and Ultraflex joints are easily immobilised at a chosen position by the operation of a locking switch or insertion of a locking pin. The ORLAU CCD orthosis is held in a fixed flexed position by a Velcro strap.

Availability/training requirements. Table I summarises the factors to consider when choosing an orthosis. It indicates that the supply of the ORLAU and Ultraflex systems is authorised only for clinical teams, the staff of which has attended the training courses run by these organisations. 
Table I. A summary of the various features of available orthoses

\begin{tabular}{lllllll}
\hline System & Stock or custom-made & $\begin{array}{l}\text { Single/two- } \\
\text { joint control }\end{array}$ & $\begin{array}{l}\text { Uniform } \\
\text { output }\end{array}$ & $\begin{array}{l}\text { Measure of } \\
\text { moment in Nm }\end{array}$ & $\begin{array}{l}\text { Lock in } \\
\text { flexion }\end{array}$ & Availability \\
\hline Dynasplint & Stock & Single & No & No & No & Ex-stock \\
EMPI & Stock & Single & Yes & No & Yes & $\begin{array}{l}\text { Ex-stock } \\
\text { Through trained } \\
\text { clinicians } \\
\text { ORLAU }\end{array}$ \\
Custom-made & Both & No & Yes & Yes & Through trained \\
clinicians
\end{tabular}

The table does not include a comparison of the cost of purchase since this may vary significantly according to local commercial factors, import duties and taxes.

\section{Discussion}

Cerebral palsy/neurological conditions. Contractures can be due to changes in the contractile or connective-tissue components of the muscle or to those of the capsule and intraarticular structures. In cerebral palsy and in neurological conditions the spasticity and shortening of muscles which cross two or more joints form a major component of many contractures. Hence, while stretching gastrocnemius it is necessary to control the knee as well as the position of the ankle. This is usually achieved by a knee-ankle-foot orthosis.

Maintaining constant torque through the joint range. Some of the available springs cannot provide a constant torque throughout the range. Thus, as the contracture decreases, the angle at which the orthosis is required to act is reduced. It therefore delivers a lower torque and so reduces the stretching effect as it moves into the inner range. These orthoses will need adjustment in order to maintain the level of torque and take advantage of the improvement in the range of movement.

Measurement of torque. Clinicians may wish to know the torque applied to the joint so that comparison can be made between the amount produced on different occasions, in different patients and by different orthoses. Although a simple dial setting is helpful for clinical use, the moment may be measured directly or a conversion chart used to relate the moment to the angle of action. This will assist in evaluating the relative merits of orthotic regimes.

Length of treatment. Although total end-range time is important, ${ }^{25}$ there are other factors which need to be considered in recommending a regime of treatment. These include the level of comfort and the need to maintain activities of daily living, including work and educational pursuits, while reducing the restrictions caused by the use of the orthosis. Although the use of stretching orthoses as night splints may be effective, the interruption to sleep and independent personal hygiene may render this inappropriate for some users.

Beneficial effects can be achieved in some conditions by using a stretching orthosis for one hour per day. ${ }^{18,37}$ This is likely to improve compliance as such use can be accommodated within a 'normal' lifestyle provided that the appliance is worn during sedentary activity. Williams ${ }^{19}$ has shown that counteracting immobilisation which causes loss of sarcomeres, can be achieved by stretching the limb to the extreme of its range for 30 minutes. It has been suggested that even stretching for 15 minutes is significantly better than none at all, ${ }^{42}$ and that a low-load sustained stretch produces more increase in tendon length than a high-load stretch for five minutes. ${ }^{20}$ The results of experiments on animal models ${ }^{19,20}$ appear to agree with clinical experience ${ }^{37}$ and that of Light et al. ${ }^{43}$

When there is continuous unopposed muscle activity it may be appropriate to gradually increase the use of a stretching orthosis for longer periods. An Ultraflex system can offer the opportunity to lock the joint so that periods of stretching may be interspersed with time in a fixed position short of the limit of the range.

Joint surfaces. In addition to affecting the structure of the muscle and connective tissue the application of a mechanically-generated load to the joint will generate pressure across its surface. Use of an orthosis may produce a relatively static compressive force whereas normal physiological activity will be dynamic with periodic unloading of pressure. ${ }^{44} \mathrm{Li}$ et $\mathrm{al}^{45}$ have shown that static loading of 84 $\mathrm{kPa}$ for 24 hours inhibited the synthesis of glycosaminoglycans and DNA in cultured samples of cartilage. Akeson et $\mathrm{al}^{46}$ noted thinning of cartilage after immobilisation for two weeks. Fukabayashi and Kurosawa ${ }^{47}$ found that applying a load directly to knees in amputated limbs gave a peak value of $3 \mathrm{MPa}$ when the knee was loaded at 1000 N. Park, Krebs and $\mathrm{Mann}^{48}$ used an implanted prosthesis to measure the pressure on the acetabular cartilage in vivo, finding that maximum pressures during the stance phase of gait were in the order of $5 \mathrm{MPa}$. Hence, dynamically, the cartilage is instantly loaded at much higher levels than was observed by Li et al. ${ }^{45}$ The orthoses which we have discussed generate much lower pressures than these values but still maintain static load. Prolonged use should be undertaken with caution to limit compressive loading and its effect on the maturation of the cartilage.

Many contractures may still need operative treatment but patients may also benefit from less invasive management. Dynamic orthoses complement and could supersede the current forms of conservative treatment. Each of the range of devices now available commercially has its own particular characteristics and the clinician must assess their various features before arriving at the device which is best suited. Successful treatment will depend on use of the appropriate device with a suitable regime of treatment. 
Dynamic orthoses may be used in conjunction with antispastic medication or muscle-lengthening surgery. At present much of our understanding of muscle physiology in response to immobilisation and stretching is based on experiments on animals. While understanding of joint and muscle structure is improving, ${ }^{42,44,49,50}$ more research into the biomechanics and efficiency of orthoses and of the responses of human muscle at a cellular level is needed to develop confidence in identifying the appropriate use of these appliances.

\section{References}

1. Yarkony GM, Sahgal V. Contractures: a major complication of craniocerebral trauma. Clin Orthop 1987;219:93-6.

2. Shelbourne K, Patel DV, Martini DJ. Classification and management of arthofibrosis of the knee after anterior cruciate ligament reconstruction. Am J Sports Med 1996;24:857-62

3. DeHaven KE, Cosgarea AJ, Sebastianelli WJ. Arthrofibrosis of the knee following ligament surgery. Instr Course Lect 2003;52:369-81.

4. Christensen CP, Crawford JJ, Olin MD, Vail TP. Revision of the stiff total knee arthroplasty. J Arthroplasty 2002;17:409-15.

5. Yip B, Stewart DA, Roberts MA. The prevalence of joint contractures in residents in NHS continuing care. Health Bulletin 1996;54:338-43.

6. Pandyan AD, Cameron M, Powell J, Stott DJ, Granat MH. Contractures in the post-stroke wrist: a pilot study of its time course of development and its association with upper limb recovery. Clin Rehabil 2003;17:89-95.

7. Hoffer MM, Knobel RT, Roberts R. Contractures in cerebral palsy. Clin Orthop 1987;219:70-7.

8. Dalyan M, Sherman A, Cardenas DD. Factors associated with contractures in acute spinal cord injuries. Spinal Cord 1998;36:405-8.

9. McDonald C. Limb contractures in progressive neuromuscular disease and the role of stretching, orthotics and surgery. Phys Med Rehabil Clin N Am 1998;9:187-211.

10. Lu H, Mow CS, Lin J. Total knee arthroplasty in the presence of severe flexion contracture: a report of 37 cases. J Arthroplasty 1999;14:775-80.

11. Farmer SE, James $\mathbf{M}$. Contractures in orthopaedic and neurological conditions: a review of causes and treatment. Dis Rehabil 2001;23:549-58.

12. Richard R, Miller S, Staley M, Johnson RM. Multimodal versus progressive treatment techniques to correct burn scar contractures. J Burn Care Rehabil 2000;21: 506-12.

13. Gracies J-M. Pathophysiology of impairment in patients with spasticity and use of stretch as a treatment of spastic hypertonia. Phys Med Rehabil Clin N Am 2001;12 747-68.

14. Harvey LA, Herbert RD. Muscle stretching for treatment and prevention of contracture in people with spinal cord injury. Spinal Cord 2002;40:1-9.

15. Beals RK. Treatment of knee contracture in cerebral palsy by hamstring lengthening posterior capsulotomy and quadriceps mechanism shortening. Dev Med Child Neurol 2001;43:802-5.

16. Stallard J, Major RE, Butler PB. Orthopaedic device for the treatment of contracture. British Patent 2216799, 1991.

17. Moore P, Major R, Stallard J, Butler PB. Contracture correction device for arthrogryposis. Physiotherapy 1990;76:303-5

18. Farmer SE, James $\mathbf{M}$. Contracture correction using mechanically applied torques: a report to the NHS Management Executive by Orthotic Research and Locomoto Assessment Unit, Oswestry, Shropshire and The Centre for Health Planning and Management, Keele University, Staffordshire 1997:23-7.

19. Williams PE. Use of intermittent stretch in the prevention of serial sarcomere loss in immobilised muscle. Ann Rheum Dis 1990;49:316-17.

20. Warren CG, Lehmann JF, Koblanski N. Heat and stretch procedures: an evaluation using tail tendon. Arch Phys Med Rehabil 1976;57:122-6.

21. Williams PE, Catanese T, Lucey EG, Goldspink G. The importance of stretch and contractile activity in the prevention of connective tissue accumulation in muscle. J Anat 1988:158:109-14.
22. De Deyne PG, Meyer R, Paley D, Herzenberg JE. The adaptation of perimuscular connective tissue during distraction osteogenesis. Clin Orthop 2000;379:259-69.

23. Booth CM, Cortina-Borja MJF, Theologis TN. Collagen accumulation in muscles of children with cerebral palsy and correlation with severe spasticity. Dev Med Child Neurol 2001;43:314-20.

24. Alter MJ. Connective tissue: a limiting factor of flexibility. In: Science of flexibility. Second ed. Leeds: Human Kinetics 1996:39-58.

25. Flowers KR, LaStayo P. Effect of total end range time on improving passive range of motion. J Hand Ther 1994;7:150-7.

26. McClure PW, Blackburn LG, Dusold C. The use of splints in the treatment of joint stiffness: biologic rationale and an algorithm for making clinical decisions. Phys Ther 1994; 74:1101-7

27. Anderson JP, Snow B, Dorey FJ, Kabo JM. Efficacy of soft splints in reducing severe knee flexion contractures. Dev Med Child Neurol 1988:30:502-8.

28. Scott OM, Hyde SA, Goddard C, Dubowitz V. Prevention of deformity in Duchene muscular dystrophy: a prospective study of passive stretching and splintage. Physiotherapy 1981;67:177-80.

29. Bonutti PM, Windau JE, Ables BA, Miller BG. Static progressive stretch to reestablish elbow range of motion. Clin Orthop 1994;303:128-34.

30. Gelinas JJ, Faber KJ, Patterson SD, King GJW. The effectiveness of turnbuckle splinting for elbow contracture. J Bone Joint Surg [Br]2000;82-B:74-8.

31. Grissom SP, Blanton S. Treatment of upper motorneuron plantarflexion contractures by using an adjustable ankle foot orthosis. Arch Phys Med Rehabil 2001;82:270-3.

32. Hepburn GR. Case studies: contracture and stiff joint management with dynasplint J Orthop Sports Phys Ther 1987;8:498-504.

33. Steffen TM, Mollinger LA. Low-load, prolonged stretch in the treatment of knee flexion contractures in nursing home residents. Phys Ther 1995;75:886-97.

34. Charlton P, Ferguson D, Peacock C, Stallard J. Preliminary clinical experience of a contracture correction device. Prosthet Orthot Int 1999;23:163-8.

35. Keeping P, Major R. Use of a gas spring contracture correction orthosis for the management of a fixed flexion contracture of the elbow. Prosthet Orthot Int 1999;23:82-4

36. ORLAU Manual. The contracture correction device for treatment of knees. Oswestry UK ORLAU Publishing Ltd, 2003.

37. Bromwich W, Farmer SE, Forward M, Roberts APR, Patrick JH. Mechanically applied stretch in the treatment of contractures: preliminary results [abstract] Physiotherapy 2002;88:55.

38. DeHarde M. Orthotic management of upper extremity deformity of a C5-C6 SCl spas tic quadriplegia: a case report [abstract]. ISPO ICth World Congress, Amsterdam, The Netherlands.

39. Ultraflex Europe. Training manual. Dirame Ortho. Brussels, Belgium: Ultraflex Systems Inc, 2000.

40. Nuismer BA, Ekes AM, Holm MB. The use of low-load prolonged stretch devices in rehabilitation programs in the pacific north west. Am J Occup Ther 1997:51:538-43

41. EMPI. Advance Dynamic ROM instruction for use manual. St. Paul, Minnesota: Empi Inc, 1998.

42. Leiber R. Skeletal muscle structure, function and plasticity: the physiological basis of rehabilitation. Second ed. Baltimore: Lippincott, Williams \& Wilkins, 2002:179-84.

43. Light KE, Nuzik S, Personius W, Barstrom A. Low-load prolonged stretch vs. highload brief stretch in treating knee contractures. Phys Ther 1984;64:330-3.

44. Wong M, Carter DR. Articular cartilage functional histomorphology and mechanobiology: a research perspective. Bone 2003;33:1-13

45. Li KW, Williamson AK, Wang AS, Sah RL. Growth responses of cartilage to static and dynamic compression. Clinical Orthop 2001;391(Suppl):34-48.

46. Akeson WH, Amiel D, Abel MF, Garfin SR, Woo SL-Y. Effects of immobilisation on joints. Clin Orthop 1987;219:28-37.

47. Fukubayashi T, Kurosawa $\mathbf{H}$. The contact area and pressure distribution pattern of the knee: a study of normal and osteoarthritic knee joints. Acta Orthop Scand 1980; 51:871-9.

48. Park S, Krebs DE, Mann RW. Hip muscle co-contraction: evidence from concurrent in vivo pressure measurement and force estimation. Gait Posture 1999;10:211-22.

49. Grodzinsky AJ, Levenston ME, Jin M, Frank EH. Cartilage tissue remodelling in response to mechanical forces. Ann Rev Biomed Eng 2000;2:691-71.

50. Fry NR, Childs CR, Eve LC, et al. Accurate measurement of muscle belly length in the motion analysis laboratory: potential for the assessment of contracture. Gait Pos ture 2003:17:119-24. 